\title{
Late referral for diabetic retinopathy screening in general practice
}

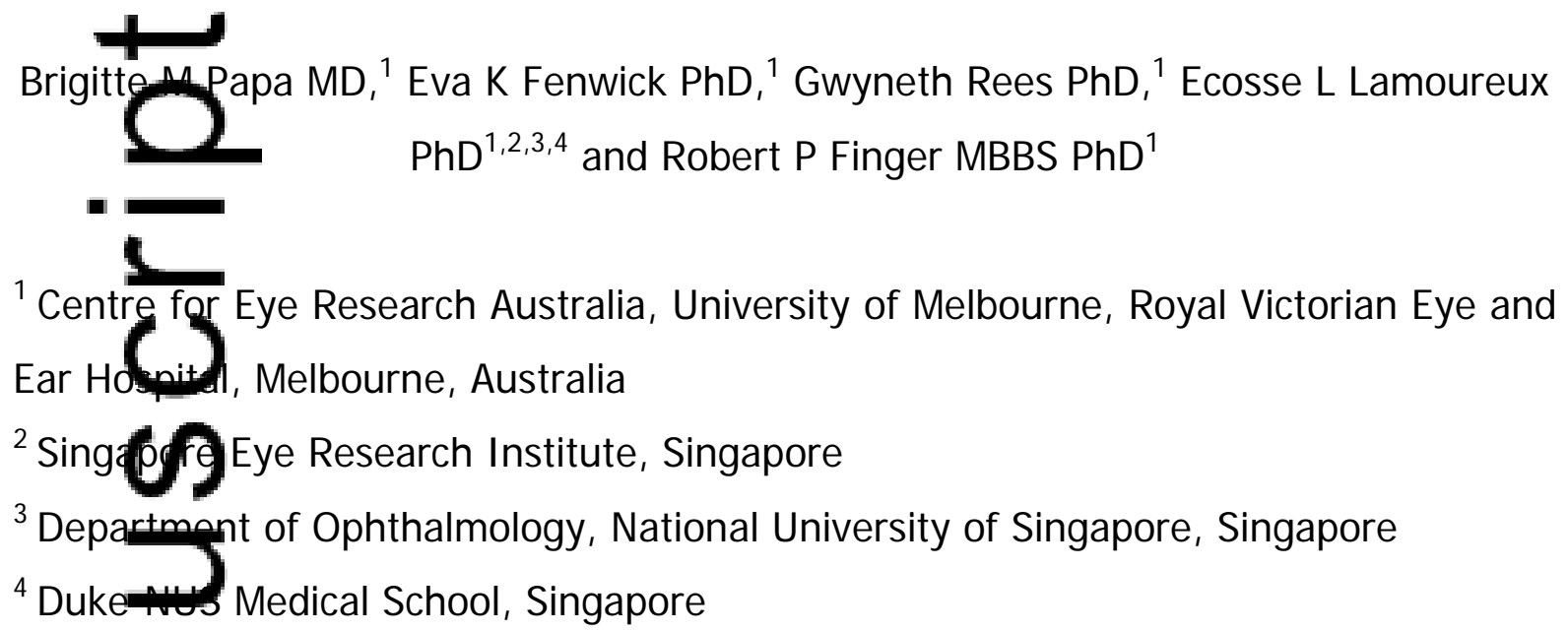

${ }^{1}$ Centre for Eye Research Australia, University of Melbourne, Royal Victorian Eye and Ear Hospital, Melbourne, Australia

${ }^{2}$ Sing $\mathrm{D}$ Eye Research Institute, Singapore

${ }^{3}$ Departmont of Ophthalmology, National University of Singapore, Singapore

${ }^{4}$ Duke-wodical School, Singapore

Correspondence: Robert P. Finger, University of Bonn, Dept. of Ophthalmology, Ernst-Abostr. 2, D-53127, Bonn, Germany

Emaiı. Robert.Finger@ukb.uni-bonn.de

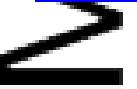

Received 16 J une 2016; accepted 22 J une 2016

Conflic nfinterest: None

Fundir g Sources: The study was supported by the Charles Viertel Charitable Foundation the Lloyd and Kathleen Ansell Ophthalmology Foundation and the Manki_wicz_Zelkin Fellowship of the University of Melbourne to Dr Finger. CERA recelvesoperational I nfrastructure Support from the Victorian Government. Dr Rees is funded by National Health and Medical Research Council Career Development Award 1061801.

This is the author manuscript accepted for publication and has undergone full peer review but has not been through the copyediting, typesetting, pagination and proofreading process, which may lead to differences between this version and the Version of Record. Please cite this article as doi: $10.1111 /$ ceo.12798 
Diabetes care, in accordance with recommended guidelines, which includes regular eye examinations, has been shown to significantly reduce the occurrence of vision loss and blindness in persons with diabetes ${ }^{1}$. Despite this evidence, diabetic retinopathy (DR) remains a leading cause of blindness in working-aged adults in Australia.

Since 2008, the Australian National Health and Medical Research Council (NHMRC) guidel diagnosis of type 2 diabetes and at biennially thereafter ${ }^{2}$. Yet, a recent Australian study found one in three people (wit) diabetes reported not having had an eye test within the past 2 years ${ }^{3}$.

General practitioners (GPs) are on the front line to safeguard individuals from vision loss assodated with diabetes, by coordinating the early detection and timely treatm of diabetic retinopathy (DR). In this study we examined current GP management practices for DR screening in adherence with the Australian NHMRC guide/(ब्ड)

A crossectional survey of 598 GPs in Victoria was conducted in January 2014. GPs were identified from consenting individuals with diabetes from another research projed ${ }^{4}$. The survey comprised 12 multiple-choice and open-ended questions relating $D R$ screening of the specific individual involved and general DR screening referralyactices. A total of 198 responses to the survey were received (of 598, 33\% respor se rate). Of these, 175 were complete (of 598, 29\% participation rate).

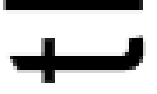

The meery period between the diagnosis of diabetes and first eye referral was 3.1 years (standard deviation [SD] 5.1 years). Over half (53\%) of GPs reported that they refe person newly diagnosed with diabetes for an eye check at the time of diagnosis. However, $23 \%$ of GPs stated they refer patients for a first eye check 1 
year or more after initial diagnosis of diabetes. Almost all GPs (97\%) reported to refer patients with type 2 diabetes at least biennially for DR screening.

Communication with eye care providers was inconsistent: only $55 \%(n=96)$ of GPs verified patient uptake of the first eye referral and 39\% ( $n=68)$ confirmed receiving a report back from the eye health professional following this first eye assessment.

\section{$\bigcirc$}

Nearly meif of GPs were interested in being involved in a national screening programme for DR (42\%). The barriers to DR screening cited by GPs were lack of educa(on)elated to diabetes and its complications for patients (34\%); lack of GP skills $\mathrm{g}$ fucation (22\%); lack of time (20\%); lack of a recall system (ie. reminders for GPS ard patients; $13 \%$ ) and cost (13\%).

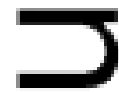

The aye delay of 3.1 years for an initial diabetes eye exam found in this survey is alarming, given that deferral in screening is significantly associated with more sever_ CBupon first assessment ${ }^{5}$. GP-described high referral rates at least biennially do within past 2 years ${ }^{3}$. It is possible that GP overestimation of referrals; breakdown in the referral chain and challenges in utilising the referral could contrikute to this disparity.

A limition of our study is the relatively low response rate. This increases the possib (ity of response bias and may present an overly optimistic picture, limiting the generalisability of our results to the broader GP population.

This is tne first cross-sectional survey of DR referral practices of Australian GPs, in comaris on with current NHMRC guidelines. We found our sample of GPs did not adhere closely to NHMRC guidelines for DR screening referral at diagnosis of 
diabetes, and suboptimal communication with eye care providers was revealed. This study signals the need for better systems of care to support DR screening and, ultimately, improve long-term visual outcomes for persons with diabetes.

\section{Acknowledgements}

We gratefully acknowledge the assistance of Kathy Fotis at the Centre for Eye Resea ch Alustralia.

\section{REFERENCES}

1. Sloa) FA, Grossman DS, Lee PP. Effects of Receipt of of GuidelineRegmmended Care on Onset of Diabetic Retinopathy and Its Progression. Uphthalmology 2009; 116: 1515-21, 21 e1-3.

2. Mitdell P, Foran S. Guidelines for the Management of Diabetic Retinopathy. -Ageing Ha, ed.Guidelines for the Management of Diabetic Retinopathy: TmeNational Health and Medical Research Council, 2008.

3. LCfiza MF, Hodgson LA, Fenwick EK, Kawasaki R, Audehm R, Wang JJ, Wong Ty Lamoureux EL. Feasibility of screening for diabetic retinopathy at an Anstralian pathology collection service: a pilot study. Med J Aust 2013; 198 : 97-9.

4. Lamoureux EL, Fenwick E, Xie J, McAuley A, Nicolaou T, Larizza M, Rees G, fureshi S, Wong TY, Benarous R, Dirani M. Methodology and early findings of Diabetes Management Project: a cohort study investigating the barriers to optimal diabetes care in diabetic patients with and without diabetic retimopathy. Clin Experiment Ophthalmol 2012; 40: 73-82.

5. Stratton IM. Delay in diabetic retinopathy screening mincreases the rate of detection of referable diabetic retinopathy. Diabetic TII dicine 2014; 31: 439-42. 


\section{University Library}

\section{- M M N E R VA A gateway to Melbourne's research publications}

Minerva Access is the Institutional Repository of The University of Melbourne

Author/s:

Papa, BM;Fenwick, EK;Rees, G;Lamoureux, EL;Finger, RP

Title:

Late referral for diabetic retinopathy screening in general practice

Date:

2016-12-01

Citation:

Papa, B. M., Fenwick, E. K., Rees, G., Lamoureux, E. L. \& Finger, R. P. (2016). Late referral for diabetic retinopathy screening in general practice. CLINICAL AND EXPERIMENTAL OPHTHALMOLOGY, 44 (9), pp.867-868. https://doi.org/10.1111/ceo.12798.

Persistent Link:

http://hdl.handle.net/11343/291545 